\title{
METODOLOGIAS DE PREPARAÇÃO DE CORPOS DE PROVA PARA ESTUDOS GEOLÓGICO-GEOTÉCNICOS DE SILTITOS LAMINADOS (GRUPO ITARARÉ)
}

\author{
PREPARATION METHODOLOGIES OF SPECIMENS APPLIED TO GEOLOGICAL- \\ GEOTECHNICAL STUDIES OF LAMINATED SILTSTONES (ITARARÉ GROUP)
}

\section{Rogério Pinto RIBEIRO, João Cândido Valenga PARIZOTTO, Antenor Braga PARAGUASSÚ}

Escola de Engenharia de São Carlos da Universidade de São Paulo (EESC/USP). Av. Trab. São Carlense, 400 - Parque Arnold Schimidt, São Carlos - SP, CEP. 13566-590.Email: rogerioprx@ sc.usp.br; jcvparizotto@gmail.com; nonus@sc.usp.br

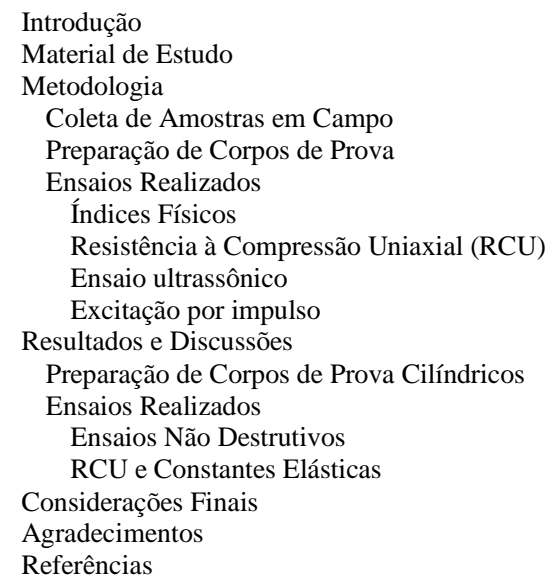

RESUMO - O presente trabalho destaca as dificuldades e aponta soluções para a obtenção de corpos de provas visando estudos geológicos e geotécnicos de rochas brandas. Trata-se de uma das operações mais complexas na temática destes materiais, especialmente quando elas se mostram muito susceptíveis à desagregação com mínimas variações da umidade relativa do ar. Diante destas constatações, é apresentada metodologia experimental envolvendo a extração de corpos de prova prismáticos e cilíndricos para ensaios destrutivos e não destrutivos (propagação de ondas) em siltitos argilosos do Grupo Itararé. A validade dos procedimentos adotados bem como as vantagens das amostras cilíndricas são discutidas, assim como os valores da resistência à compressão uniaxial e dos módulos estático e dinâmico de deformabilidade. Destaca-se a importância deste estudo uma vez que estes materiais problemáticos afloram nas imediações do aeroporto de Viracopos (Campinas) e também em parte do traçado previsto do Trem de Alta Velocidade (TAV) brasileiro, onde serão realizadas obras de engenharia tais como fundações, cortes e aterros, entre outras.

Palavras-chave: rochas brandas, siltitos argilosos, corpos de prova, geomecânica.

ABSTRACT - The present work highlights the difficulties and provides solutions to the acquisition of specimens aiming geological and geotechnical studies of soft rocks. This is one of the most complex operations on the subject of these materials, particularly when they seem very susceptible to disaggregation with minimum variations of air relative humidity. In the face of the aforementioned, an experimental methodology is presented, involving the extraction of prismatic and cylindrical specimens for destructive and nondestructive tests (wave propagation) on clayey siltites which belong to the Itararé Group. The validation of the adopted procedures as well as the advantages of the cylindrical specimens are discussed. The values of uniaxial compressive strength and both static and dynamic Young's modulus are also discussed. The importance of the present study lies in the fact that these problematic materials are found in the surroundings of the Viracopos airport (Campinas) and also in part of the predicted path of the Brazilian High Speed Train, where civil work like foundations, cuts, embankments and others will be performed.

Keywords: Soft rocks, clayey siltstones, specimens, geomechanics.

\section{INTRODUÇÃOO}

Por se encontrarem justamente na interface de maciços terrosos e rochosos, e ainda por levar em conta duas vertentes envolvendo profissionais com diferentes pontos de vista quanto ao entendimento sobre o que é uma rocha branda (ISRM, 1978a), tem-se variada gama de classificações e interpretações, dificultando o objetivo comum, que é a execução de obras com projetos seguros e parâmetros técnicos sensatos (Parizotto et al., 2014).

Neste contexto, as rochas sedimentares brandas têm um grande papel e abrangência no 
Brasil, foram e ainda são substratos terrosos ou rochosos que compõe fundações de barragens, de pontes e de estruturas prediais, assim como escavações a céu aberto e subterrâneas de ferrovias, rodovias, empreendimentos hidrelétricos, entre outros (ABGE, 1988; Dobereiner, 1990; Kanji, 2014). É oportuno estudar este tema porque há uma demanda substancial de obras de engenharia no Brasil, como, por exemplo, o Trem de Alta Velocidade (TAV), que contempla o projeto de um serviço de transporte ferroviário de passageiros de grande eficiência que conectará as cidades do Rio de Janeiro, São Paulo e Campinas.

Conforme ilustrado na figura 1 , o traçado do TAV interceptará siltitos argilosos do Grupo Itararé (Carbonífero Superior/Permiano Inferior) aflorantes em uma faixa de aproximadamente 26 km que se estende dentro dos limites do município de Campinas. De acordo com o Serviço Geológico do Brasil (CPRM, 2009), são várias soluções de engenharia projetadas para essa extensão: túneis $(3,4 \mathrm{~km})$, pontes $(2,2 \mathrm{~km})$ e sucessivos cortes e aterros $(20,4 \mathrm{~km})$. Estudos preliminares (CPRM, 2009; IPT, 2010) são claros em apontar o potencial expansível e colapsível nessa faixa. Além disso, sugere-se atenção à escavação do túnel que, embora não tenha confronto direto com a área de influência do aeroporto de Viracopos, medidas de controle de recalques e do N.A. devem ser realizadas. Outro grande empreendimento decorrente de ações governamentais, que poderá ocorrer envolvendo obras nos siltitos estudados, é a renovação de concessões ferroviárias que inclui a malha paulista de ferrovias.

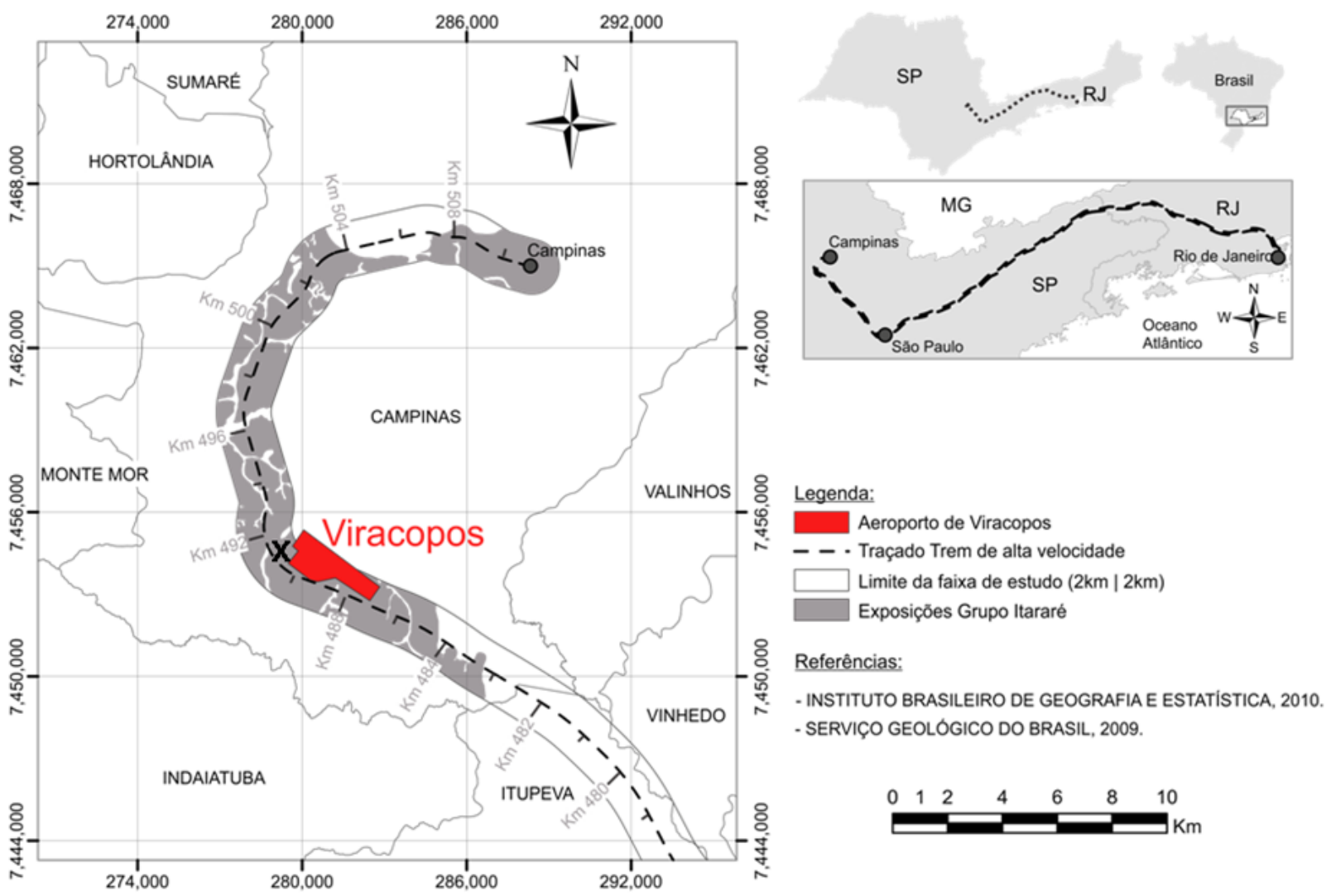

Figura 1 - Traçado esquemático do TAV destacando áreas de exposição (em tom cinza) do Grupo Itararé na região de Campinas. Modificado de IBGE (2010) e CPRM (2009). Detalhe "X" mostra local aproximado de amostragem.

Os siltitos argilosos do Grupo Itararé se apresentam físseis e expansivos e, por esse motivo, são facilmente desagregáveis em razão dos ciclos naturais de umedecimento e secagem, o que dificulta sua caracterização geomecânica. Este fenômeno pode causar problemas geotécnicos diversos, tornando esta caracterização importante. Estas peculiaridades são bem destacadas por Galván (1999) e Kanji
(2014), mostrando a necessidade de melhor entender os comportamentos geológico, hidráulico, mecânico, físico e químico de rochas brandas argilo-siltosas, de modo a possibilitar correlações e análises mais sensatas sobre o comportamento destes geomateriais em relação às solicitações de um dado empreendimento civil ao longo do tempo.

A grande dificuldade desse estudo está 
relacionada à obtenção de corpos de provas balizados por normativas técnicas para caracterização desta rocha de complexo comportamento geotécnico. No presente trabalho, portanto, é apresentada a técnica de obtenção desses corpos de provas necessários à determinação da resistência à compressão uniaxial e da velocidade de propagação de ondas, propriedades fundamentais em estudos geomecânicos de maciços.

\section{MATERIAL DE ESTUDO}

As coletas foram feitas em uma mineração localizada nas imediações do Aeroporto de Viracopos, onde é extraída matéria-prima, comumente denominada como "taguá", para produção de cerâmica. Com base no reconhecimento expedito de campo, a rocha foi classificada como um siltito de colorações cinza, marrom e amarela.

Os siltitos cinzas são em geral maciços e finamente laminados, com a presença localmente de camadas oxidadas e zonas com pintas esbranquiçadas, estas aparentemente constituídas de materiais sulfetados. Os siltitos de coloração marrom são predominantemente laminados (milimétricos a centimétricos) e muito mais frágeis, em função do intenso empastilhamento que promove uma acentuada desagregação no manuseio destes materiais. Sob os efeitos da ação intempérica, os siltitos cinzas adquirem coloração amarelada (Figura 2).

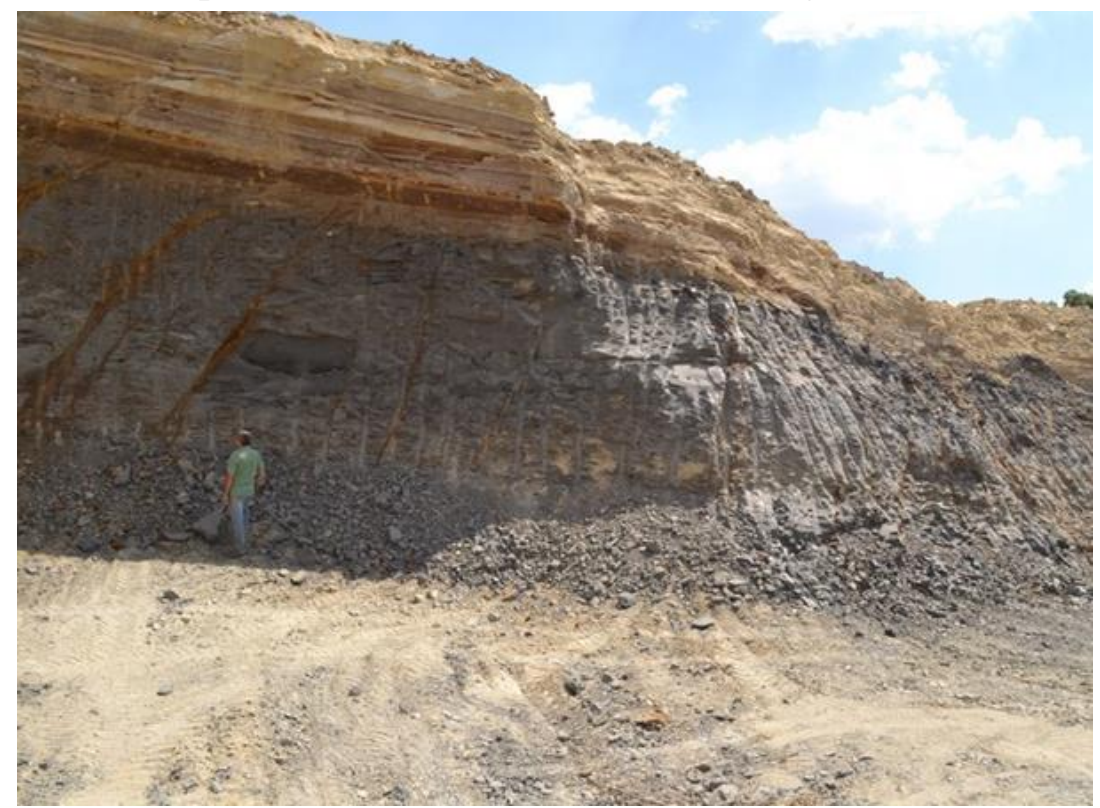

Figura 2 - Frente de lavra exibindo siltitos amarelados e acinzentados.

Com base na petrografia óptica e dados de análises térmicas diferenciais, de difração de raios $\mathrm{X}$ e de microscopia eletrônica de varredura notouse que a laminações presentes nos siltitos cinzas são bem marcadas por uma alternância de níveis mais claros e escuros, ou seja, com uma maior ou menor presença de argilominerais.

Os agregados de argilominerais pertencem ao grupo da caulinita, exibem bordas levemente esverdeadas e são cimentados por óxidos de ferro, conforme detalhe mostrado na figura 3. Os grãos de quartzo apresentam-se irregulares e/ou arredondados, com fraturas e frequentemente recobertos por óxido/hidróxidos de ferro, em geral com granulometria inferior a $30 \mu \mathrm{m}$. Considerando a granulometria fina da rocha, estas técnicas permitiram identificar que os siltitos do Grupo
Itararé são constituídos por quartzo, caulinita, opacos e óxidos/hidróxidos de ferro e magnésio, com presença subordinada de feldspato potássico, pirita, clorita, paragonita e matéria orgânica.

Estimativas da porcentagem de grãos de quartzo e de argilominerais presentes nos níveis mais claros e escuros observados em lâminas delgadas foram efetuadas com um aumento de 20x.

Em geral, os níveis mais escuros possuem de 30 a $70 \%$ de agregados de argilominerais e 20 a $40 \%$ de quartzo; as porções mais claras, em contrapartida, 5 a $40 \%$ de minerais argilosos e 60 a $90 \%$ de quartzo.

Algumas vezes, predominam minerais opacos e óxidos/hidróxidos de ferro e magnésio nas porções escuras, conformando cerca de 40 a $60 \%$ e, nas porções claras, até $10 \%$. 


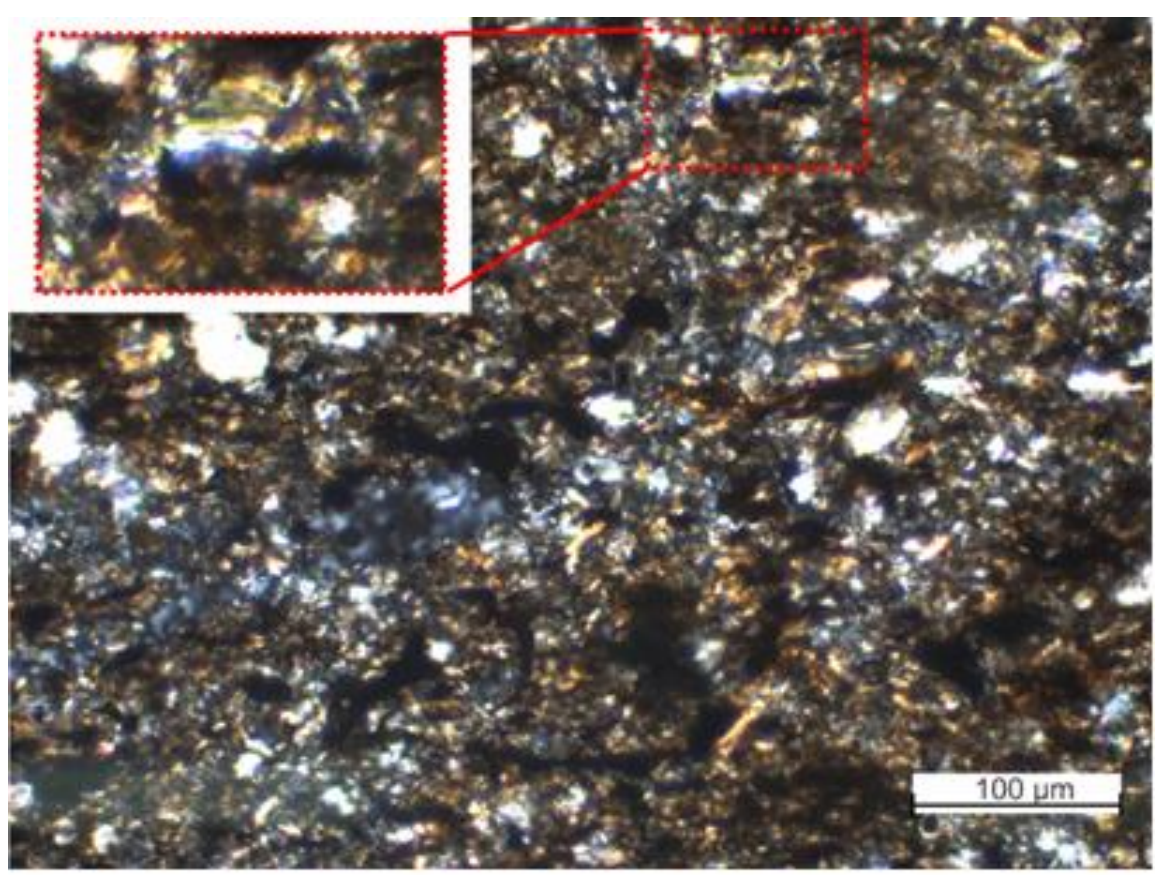

Figura 3 - Fotomicrografia com polarizadores cruzados do siltito de coloração cinza mostrando os pontos brilhantes (quartzo), porções escuras (poros) e agregados de argilomineral (caulinita) com bordas esverdeadas, melhor visualizados no detalhe.

\section{METODOLOGIA}

Além das dificuldades de amostragem, os ensaios das rochas de baixa resistência apresentam certas peculiaridades. Recorre-se frequentemente à utilização de práticas rotineiras em ensaios da mecânica dos solos ou das rochas. Porém, os equipamentos utilizados em solos são pouco robustos para a caracterização de materiais mais resistentes e, por outro lado, os empregados em rochas são muito vigorosos, apresentando pouca sensibilidade para níveis de tensões baixos.

Como bem colocado por Nóbrega (1985), a solução ideal para o procedimento de ensaios com rochas de baixa resistência requereria o desenvolvimento de técnicas especialmente criadas ou adaptadas, para que atendessem às particularidades do comportamento frágil em termos de rocha dura e resistente em comparação aos solos. Contudo, tal normativa ainda não existe. Além de quais ensaios adotar, deve-se tomar cuidado na etapa de preparação das amostras, obedecendo na medida do possível, métodos já consagrados para as rochas duras.

Com base nestas premissas, portanto, no presente trabalho são apresentadas as seguintes etapas de investigação: (1) Coleta de amostras em campo; (2) Preparação dos corpos de prova (CPs) e (3) Ensaios destrutivos (resistência à compressão uniaxial) e não destrutivos (velocidade de propagação de onda), utilizados na Mecânica das Rochas para quantificar a resistência e a deformabilidade dos materiais.

\section{Coleta de Amostras em Campo}

Dos siltitos de coloração cinza, escolhidos para estudo, foram extraídos blocos orientados de aproximadamente $50 \mathrm{~cm} \times 50 \mathrm{~cm}$ e levados ao laboratório para obtenção de CPs prismáticos e cilíndricos para ensaios geomecânicos e determinação dos índices físicos. Levou-se em conta a relativa homogeneidade tanto horizontal como vertical das camadas sedimentares, sendo assim os blocos coletados bem representaram as condições geológicas, composicionais e estruturais do maciço.

\section{Preparação de Corpos de Prova}

Nas tentativas de extração dos CPs prismáticos utilizou-se serras diamantadas, por meio de via seca e úmida. Contudo, foram inúmeras as dificuldades encontradas como, por exemplo, a altura de corte que é limitada pelo raio do disco, a dificuldade em ser deixar as faces paralelas, a rugosidade gerada em razão da espessura e da vibração do disco. Outro fator foi a intensa poeira gerada no corte a seco, pela impossibilidade de corte por via úmida, porque a amostra fissurava-se.

Essas dificuldades induziram escolher outra técnica, a obtenção de CPs cilíndricos extraídos dos blocos por meio de perfuratriz com broca diamantada (diâmetro externo de $63,5 \mathrm{~mm}$ e interno de 56,2 $\mathrm{mm}$ ). Para o dimensionamento adequado dos CPs frente aos ensaios propostos 
seguiu-se as especificações preconizadas pela ASTM e ISRM, apresentadas no item referente aos ensaios realizados. Testaram-se três metodologias de perfuração: via úmida (água) e via seca com e sem ar-comprimido. Já no corte das extremidades deste CPs cilíndricos, utilizou-se o corte a seco com serra diamantada, seguido do emprego de retífica plana (a seco) com um sistema de aspiração da poeira para garantir o paralelismo do topo e base das amostras.

\section{Ensaios Realizados}

Além dos índices físicos, foram realizados dois grupos de ensaios: resistência à compressão uniaxial conjugado à determinação do módulo de deformabilidade estático e ensaios de propagação de onda (ultrassom e excitação por impulso) para se obter o módulo de deformabilidade dinâmico dos siltitos.

\section{Índices físicos}

Os procedimentos adotados seguiram as recomendações da ISRM (1977) e da norma NBR 15845 - Parte 2 (ABNT, 2015). Os valores destes índices foram: umidade (w) de 5,7\%, massa específica natural $\left(\rho_{\text {nat }}\right)$ de $2,23 \mathrm{~g} / \mathrm{cm}^{3}$, porosidade aparente $\left(\eta_{\mathrm{a}}\right)$ de $21,9 \%$ e absorção d'água $\left(\alpha_{\mathrm{a}}\right)$ de $10,7 \%$.

\section{Resistência à Compressão Uniaxial}

Neste ensaio utilizou-se prensa servocontrolada para aplicação da carga e registro das deformações axial e radial. A taxa de carregamento foi de $6 \mathrm{KN} / \mathrm{min}$ para que os CPs rompessem em um intervalo de tempo de 2 a 15 minutos, segundo recomendações das normas D7012 (ASTM,2014) e D4543 (ASTM, 2008). As deformações axiais e radiais para a determinação das constantes elásticas $\left(E_{s}\right.$ e v) foram obtidas por meio de strain gages bidirecionais colados a meia altura do $\mathrm{CP}$.

\section{Ensaio Ultrassônico}

Os procedimentos de medição ultrassônica das ondas P seguiram as normas D2845 (ASTM, 2008), ISRM (1978a) e ISRM (2014). A configuração básica dos transdutores foi a transmissão direta pela técnica de arremesso e captura (TAC; Figura 4a), sendo utilizado um equipamento portátil (Pundit Lab da Proceq), com par de transdutores Vp de $54 \mathrm{kHz}$. Seguindo a metodologia de Parizotto (2015), todas as medidas obtidas foram exportadas para $\mathrm{o}$ software Excel e então calculadas Vp (Eq.1) e o $\operatorname{Ed}_{\mathrm{u}}$ (Eq. 2):

$$
V p=\frac{L}{t p}
$$

onde $V p$ é a velocidade das ondas $\mathrm{P} ; L$ é o comprimento do corpo de prova e tp o tempo de viagem da onda de corpo $\mathrm{P}$.

$$
V p=\sqrt{\frac{E d_{u}}{\rho}}
$$

onde $V p$ é a velocidade das ondas $\mathrm{P} ; E d_{u}$ o módulo de elasticidade dinâmico calculado pelo método ultrassônico; e $\rho$ a massa específica.
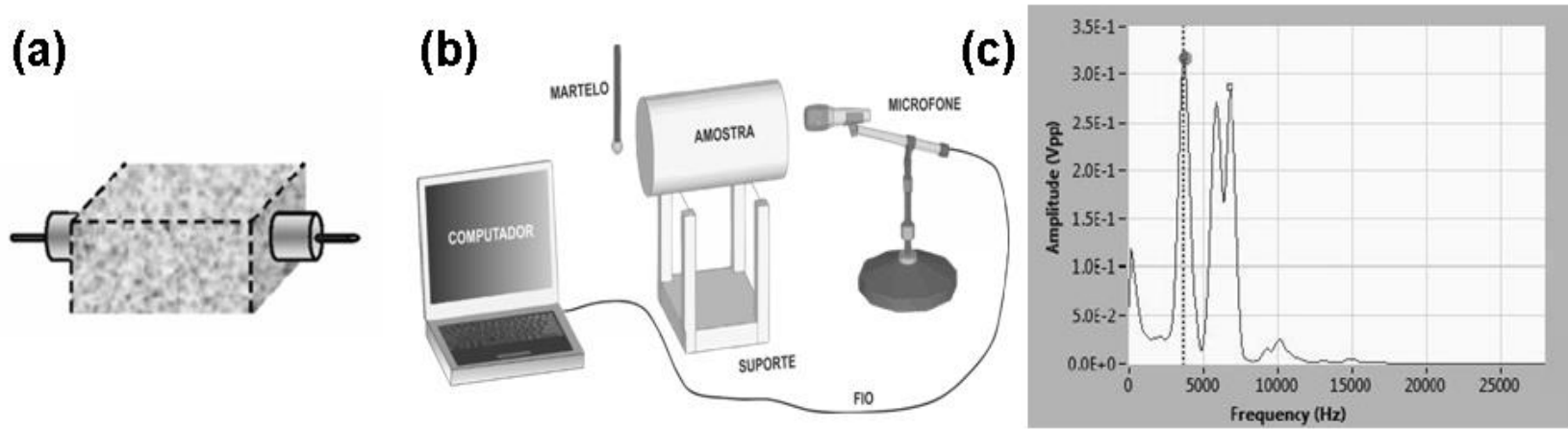

Figura 4 - a) Configuração básica dos transdutores (transmissor e receptor) usando a TAC por transmissão direta (através do CP) no ultrassom (ISRM, 2014); b) configuração do ensaio acústico (Haach et al., 2013); c) identificação das frequências naturais (Parizotto, 2015).

\section{Excitação por Impulso}

Esta técnica de uso difundido para concreto, cerâmica e metais, foi utilizada de modo complementar e se mostrou de grande valia na presente pesquisa, podendo ser recomendada também para o estudo de rochas duras, principalmente para a verificação das descon- tinuidades (fraturas, bandamento, foliação, etc.)

Neste método, os módulos elásticos são calculados a partir do som emitido pelo $\mathrm{CP}$ ao sofrer um pequeno impacto mecânico. O som ou resposta acústica são compostos pelas frequências naturais $\left(\mathrm{f}_{\mathrm{N}}\right)$ de vibração do corpo que são proporcionais aos módulos elásticos. 
As medições foram realizadas utilizando-se um sistema denominado Sonelastic ${ }^{\circledR}$. A configuração do sistema consiste em um software, um captador acústico (microfone e pedestal), um suporte para as amostras vibrarem livremente e um pulsador manual (Figura 4b).

Em resumo, com o $\mathrm{CP}$ cilíndrico devidamente fixado no suporte e o microfone disposto longitudinalmente próximo a uma das extremidades do $\mathrm{CP}$, impacta-se o pulsador manual na outra extremidade, gerando assim a leitura da vibração. O microfone, ligado ao computador via USB, capta as amplitudes no domínio do tempo que são transformadas por meio do software ATCP Sonelastic ${ }^{\circledR}$ em um gráfico de frequências naturais $\left(f_{N}\right)$ e amplitudes máximas (vpp). O módulo de elasticidade dinâmico $\mathrm{Ed}_{\mathrm{L}}$, ou neste trabalho denominado $\mathrm{Ed}_{\mathrm{s}}$, em razão do nome do sistema, é calculado a partir da frequência de maior amplitude, conforme observado na figura $4 \mathrm{c}$, a partir da Eq.3:

$$
E d_{L}=5,093 \times \frac{L}{D^{2}} \times m \times f_{N}^{2}
$$

onde $m$ - massa; $D$ - diâmetro; $L$ - comprimento do $\mathrm{CP} ; f_{N}$ - frequência natural fundamental longitudinal, em hertz.

\section{RESULTADOS E DISCUSSÕES}

\section{Preparação de Corpos de Prova Cilíndricos}

Em testes preliminares com as três metodologias de perfurações nos blocos para obtenção dos CPs, a seguir apresentadas, observou-se as seguintes dificuldades: a) Via úmida: alteração das condições de umidade e aparecimento de fissuras durante a extração obtendo-se CPs com altura máxima de apenas 4 cm; b) Via seca sem ar-comprimido: superaquecimento da broca diamantada e do cálice, falta de remoção dos fragmentos produzidos na perfuração e travamento do extrator, furos perdidos; c) Via seca com arcomprimido: eficiente refrigeração da broca e remoção dos fragmentos, excessiva produção de poeira, podendo gerar danos à refrigeração do extrator, altura máxima recuperada de $7 \mathrm{~cm}$, em função da vibração excessiva da broca.

Destas alternativas, a perfuração via seca com ar-comprimido mostrou-se mais eficiente, destacando-se as seguintes providências tomadas: (i) Implantação de tubulação com ar comprimido conectada a um filtro com capacidade de $20 \mathrm{kbar}$ para reter qualquer tipo de umidade que ainda houvesse na tubulação, (ii) Usinagem de uma nova peça de acoplamento do cálice ao extrator para minimizar quebras mecânicas dos testemunhos e (iii) Adaptação de caixa de isolamento ao redor do bloco rochoso para minimizar a contaminação do ambiente com poeira.

Junto à caixa, foram deixadas apenas entradas para a broca, além de orifícios laterais para inserção de canalização de aspiradores de pó, que sorviam grande parte do resíduo gerado durante a perfuração (Figura 5).

Apesar das características intrínsecas e adversas do siltito para preparação de corpos de prova, em especial a eminente fissilidade por conta de leitos com maior predominância de argilominerais, com a metodologia acima descrita obteve-se 32 CPs com diâmetro (D) de $56 \mathrm{~mm}$ e altura (A) entre 110 e $140 \mathrm{~mm}$, que foram utilizados para realizar os ensaios de resistência à compressão uniaxial e de propagação de onda, atendendo perfeitamente aos requisitos normativos para a determinação concomitante destas propriedades índices, conforme ilustrado na figura 6 . Os dados da tabela 1 apresentam as relações A/D com a altura, bem como a média, o desvio padrão, o coeficiente de variação, mínimo e máximo das alturas, diâmetros e razões A/D de todos os CPs. Observar que apenas 1 dos CPs obteve uma relação A/D ligeiramente abaixo do requisitado.

\section{Ensaios Realizados}

Os resultados dos ensaios não destrutivos (propagação de ondas) e da resistência à compressão uniaxial, realizados com os CPs cilíndricos obtidos por via seca com arcomprimido, a técnica de extração mais eficiente, encontram-se agrupados na Tabela 2 e são a seguir discutidos.

\section{Ensaios não destrutivos}

Com a média dos registros de tempo das amostras, calculou-se as Vp para cada CP, com velocidade média de $1.667 \mathrm{~m} / \mathrm{s}$, com $\mathrm{Cv}$ de $12,6 \%$. A partir das $\mathrm{Vp}$, calculou-se os módulos de deformabilidade dinâmico por meio do ultrassom $\left(\mathrm{Ed}_{\mathrm{U}}\right)$, com valor médio de 6,33 GPa e $\mathrm{Cv}$ de 25\%, coeficiente este alto, gerado em razão do teor de umidade (w) inserido no valor da massa específica natural ( $\left.\rho_{\text {nat }}\right)$ e da própria $V p$, ambos utilizados no cálculo do módulo EdU de cada CP. 


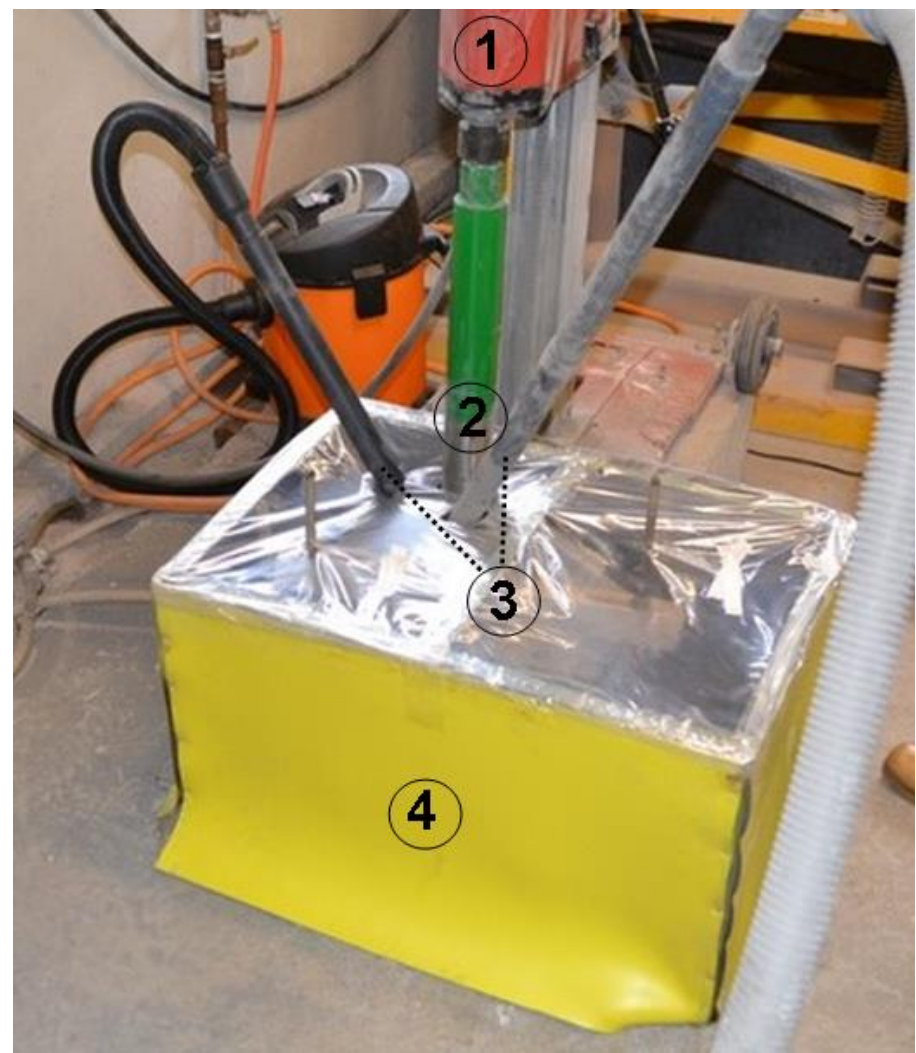

Figura 5- Sistema de extração de CPs cilíndricos via seca com ar-comprimido: (1) perfuratriz; (2) broca diamantada; (3) tubos de aspiração de pó gerado durante a perfuração e (4) caixa de isolamento contendo bloco de siltito para perfuração.
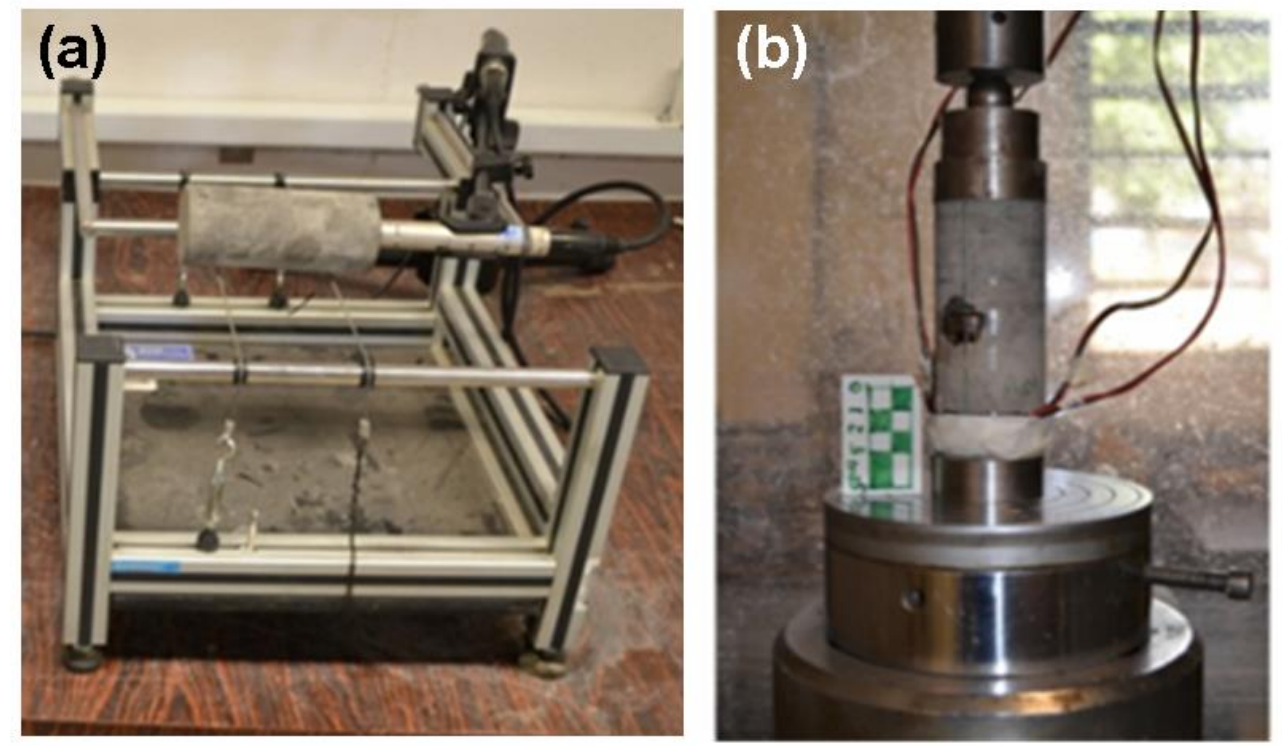

Figura 6 - Observar as características dos corpos de prova com superfícies sem rugosidade e com boa qualidade atendendo as diretrizes normativas para a determinação de a) frequência natural $f_{N}$ e b) resistência à compressão uniaxial, incluindo a determinação dos módulos de deformabilidade dinâmico e estático, respectivamente.

Tabela 1- Estatística dimensional dos corpos de prova preparados para os ensaios de propagação de ondas e de resistência à compressão uniaxial.

\begin{tabular}{c|c|c|c|c|c}
\hline \multicolumn{2}{c|}{ A } & \multicolumn{2}{c|}{ D } & \multicolumn{2}{c}{ A/D } \\
\hline Med (mm) & 128,23 & Med $(\mathrm{mm})$ & 56,23 & Med & 2,28 \\
\hline $\mathbf{C}_{\mathbf{v}}$ & $6,94 \%$ & $\mathrm{C}_{\mathrm{v}}$ & $0,13 \%$ & $\mathrm{C}_{\mathrm{v}}$ & $6,88 \%$ \\
\hline Mín $(\mathbf{m m})$ & 109,90 & Mín $(\mathrm{mm})$ & 56,10 & Mín. & 1,96 \\
\hline Máx $(\mathbf{m m})$ & 139,50 & Máx $(\mathrm{mm})$ & 56,40 & Máx. & 2,48 \\
\hline AT $(\mathbf{m m})$ & 29,60 & AT $(\mathrm{mm})$ & 0,30 & AT & 0,52 \\
\hline
\end{tabular}

Legenda: A - altura; D- diâmetro; Med- média; Min- mínimo; Max- máximo; AT- amplitude total. 
Tabela 2 - Dados estatísticos dos ensaios de propagação de ondas e de resistência à compressão uniaxial.

\begin{tabular}{c|c|c|c|c|c|c|c}
\hline Parâmetro & $\mathbf{V p}(\mathbf{m} / \mathbf{s})$ & $\mathbf{E d}_{\mathbf{u}}(\mathbf{G P a})$ & $\mathbf{f}_{\mathbf{N}}(\mathbf{H z})$ & $\mathbf{E d}_{\mathbf{s}}(\mathbf{G P a})$ & $\boldsymbol{\sigma}_{\mathbf{u}}(\mathbf{M P a})$ & $\mathbf{E}_{\mathbf{s}}(\mathbf{G P a})$ & $\mathbf{v}$ \\
\hline $\mathbf{M e d}$ & 1.667 & 6,33 & 4.878 & 3,54 & 22,3 & 1,01 & 0,31 \\
\hline Min & 1.282 & 3,62 & 3.574 & 2,01 & 10,0 & 0,5 & 0,22 \\
\hline $\mathbf{M a x}$ & 2.019 & 9,17 & 6.479 & 4,82 & 28,7 & 1,3 & 0,48 \\
\hline $\mathbf{A T}$ & 737 & 5,55 & 2.905 & 2,81 & 18,7 & 0,8 & 0,26 \\
\hline $\mathbf{S}$ & 210 & 1,58 & 796 & 0,98 & 5,0 & 0,3 & 0,08 \\
\hline $\mathbf{C}_{\mathbf{v}}(\boldsymbol{\%})$ & 12,6 & 25,0 & 16,3 & 27,8 & 16,7 & 26,8 & 25,7 \\
\hline
\end{tabular}

Legenda: $\mathrm{Vp}$ - velocidade de propagação de ondas, $\mathrm{Ed}_{\mathrm{u}}-$ módulo dinâmico ultrassônico, $\mathrm{f}_{\mathrm{N}^{-}}$frequência natural, $\mathrm{Ed}_{\mathrm{s}^{-}}$ módulo dinâmico sonelast, $\sigma_{\mathrm{u}}$ - resistência à compressão uniaxial; $\mathrm{E}_{\mathrm{s}^{-}}$módulo estático, $\mathrm{v}$ - coeficiente de Poisson; Medmédia; Min- mínimo; Max- máximo; AT- amplitude total, S- desvio padrão, $\mathrm{C}_{\mathrm{v}}$ - coeficiente de variação.

Após os ensaios realizados com o ultrassom, foram analisadas as frequências naturais $\left(\mathrm{f}_{\mathrm{N}}\right)$ geradas pela excitação por impulso utilizando-se o software Sonelast $\circledR^{\circledR}$. Para cada amostra foram realizadas 5 medições de $\mathrm{f}_{\mathrm{N}}$, sendo sua média representativa de cada $\mathrm{CP}$. Considerando-se todas as amostras, o valor médio de $\mathrm{f}_{\mathrm{N}}$ foi de $4878 \mathrm{~Hz}$, com $\mathrm{Cv}$ pouco superior ao ultrassom, de $16,3 \%$. Com os valores de $f_{N}$ para cada amostra, foram calculados os módulos $\mathrm{Ed}_{\mathrm{S}}$, obtendo-se um valor médio de 3,54 GPa e $\mathrm{Cv}$ igualmente alto, de aproximadamente $28 \%$.

Comparando-se as duas metodologias de obtenção de módulo de deformabilidade dinâmica, nota-se uma boa correlação, com $\mathrm{R}^{2} \mathrm{de}$ 0,699 (Figura 7). A média das razões entre os módulos do ultrassom e do sonelast foi de 1:1,83 com um $\mathrm{Cv}$ de $15,8 \%$.

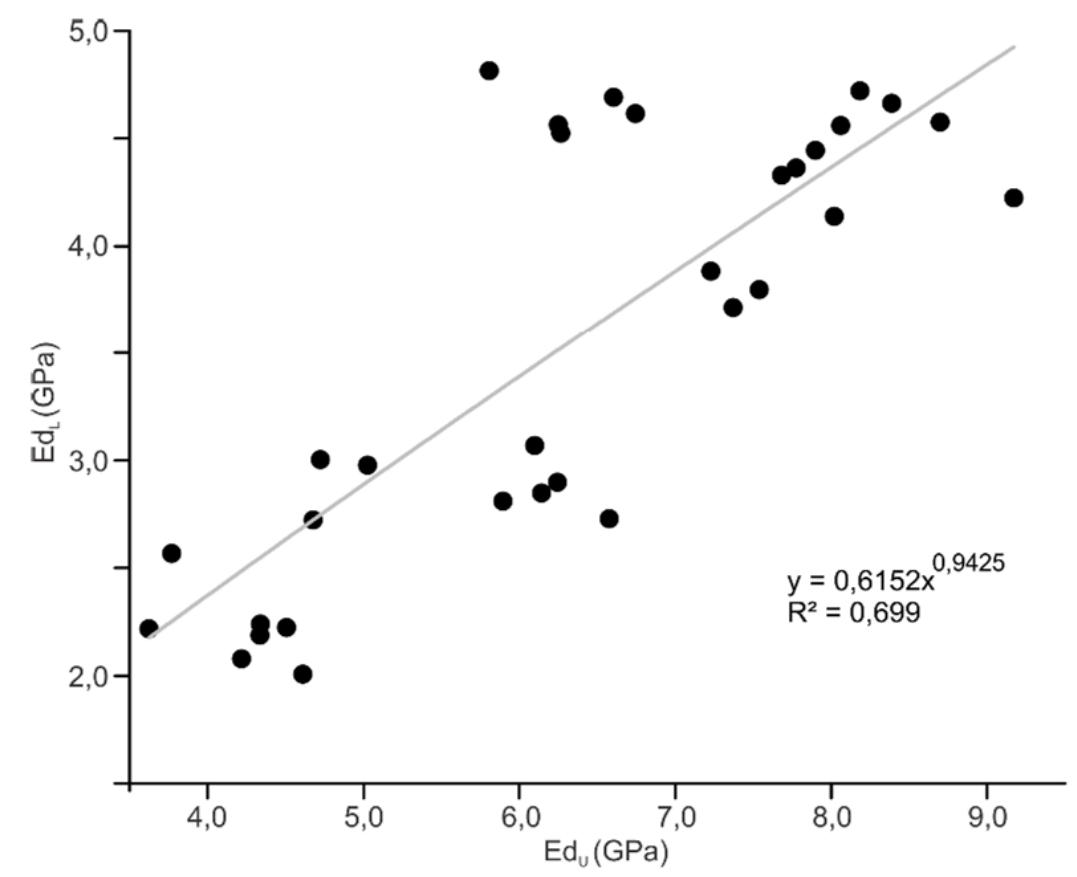

Figura 7 - Relação entre os módulos dinâmicos obtidos por meio da técnica de pulso ultrassônico e de excitação por impulso.

Resistência à compressão uniaxial e constantes elásticas

Os valores obtidos mostram que os siltitos cinzas do Grupo Itararé em condições naturais podem ser caracterizados como brandos, visto a resistência inferior a $25 \mathrm{MPa}$ (ISRM, 1978b), com $\sigma_{U}$ médio de 22,3 MPa. Mesmo em se tratando de CPs extraídos de blocos provenientes do mesmo nível estratigráfico, verifica-se o elevado Cv para os parâmetros analisados ( $\sigma_{U}$, Es e v). Ao discutir a dependência de $\sigma_{u}$ com índices físicos (teor de umidade, porosidade aparente e massa específica natural), Parizotto (2015) sugere que as variações de $\sigma_{U}$ provavelmente se associem com diferenças microestruturais particulares de cada CP. Variações semelhantes entre amostras de mesmas camadas em condições naturais também foram verificadas por Taylor (1988), cujos valores de $\sigma_{U}$ em lamitos de Coal Measures (Inglaterra) variaram de 5 a 16 $\mathrm{MPa}$, com média de 11,2 MPa e desvio padrão de 3,74 MPa. 
Comparando-se os módulos obtidos pelos métodos estático e dinâmicos, verifica-se uma maior correlação entre Es com Eds, dado a menor dispersão evidenciada pelos resultados, com $\mathrm{R}^{2}$ de 0,802 (Figura 8). Em média, a razão entre os módulos dinâmicos e estáticos foi de 1:4,12 para o método de propagação por impacto e de 1:7,05 para o ultrassônico.

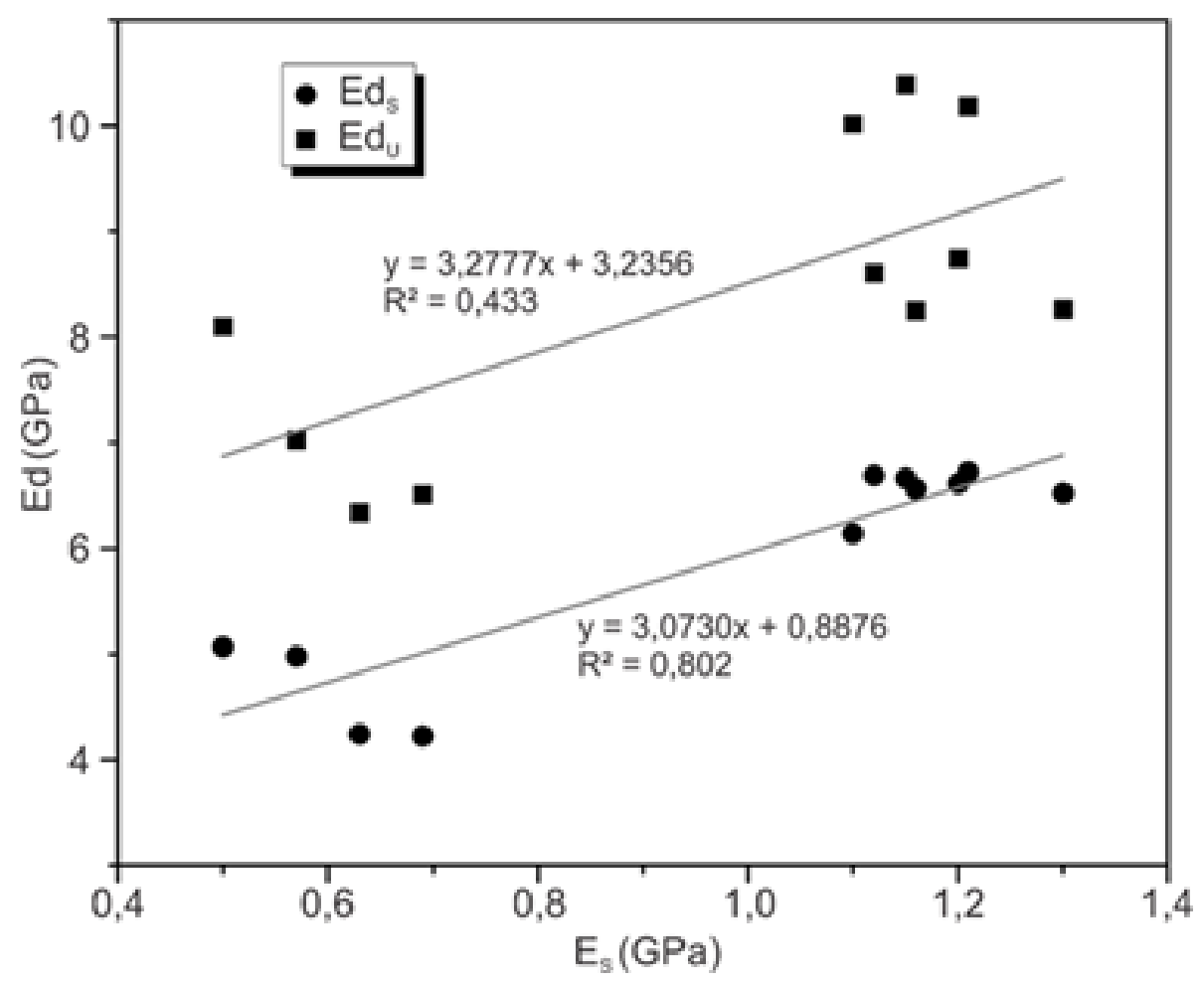

Figura 8 - Correlação entre os módulos dinâmicos e estático.

\section{CONSIDERAÇÕES FINAIS}

A amostragem em campo, a preparação de CPs e os procedimentos de ensaios laboratoriais são operações de maior complexidade na temática das rochas brandas.

Este trabalho apresentou e discutiu diferentes alternativas de extração laboratorial de CPs em blocos de siltitos do Grupo Itararé coletados em campo para ensaios de caracterização geomecânica. Verificou-se que os procedimentos laboratoriais foram bem conduzidos, resultando em CPs cilíndricos de boa qualidade, obtidos pelo método de via seca com arcomprimido, que atendendo as normas para rochas resistentes, possibilitam o estudo e interpretações destas rochas sedimentares problemáticas. Esta metodologia de preparação de CPs tem potencialidade de aplicações mais abrangentes para estudos geológicos e geotécnicos com outros tipos de rochas brandas.

Os ensaios de RCU em amostras com a umidade natural caracterizaram os siltitos do Grupo Itararé como brandos, com valores médios de 21,3 MPa, de Es 0,97 GPa e coeficiente de Poisson de 0,31. Quantos aos ensaios não destrutivos, verificou-se maior correlação com o módulo dinâmico de elasticidade $\mathrm{Ed}_{\mathrm{s}}$, calculado a partir de medições de frequências naturais com o sistema Sonelast $\AA$.

\section{AGRADECIMENTOS}

Os autores agradecem à Coordenação de Aperfeiçoamento de Pessoal de Nível superior (CAPES) pelo suporte financeiro, à Cerâmica Mingone pela permissão de amostragem em sua pedreira e aos Professores Doutores Vladimir G. Haach e Ricardo Carrazedo pela utilização dos sistemas de ultrassom e Sonelast nos laboratórios do Departamento de Engenharia de Estruturas da EESC/USP.

\section{REFERÊNCIAS}

ABGE-ASSOCIAÇÃO BRASILEIRA DE GEOLOGIA DE ENGENHARIA E AMBIENTAL. Primeiro relato do Comitê de Estudos Geotécnicos de rochas sedimentares. ABGE: São Paulo, 160 p. 1988.
ABNT-ASSOCIACAO BRASILEIRA DE NORMAS TECNICAS. NBR 15845. Rochas para revestimento. Parte 2: Determinação da densidade aparente, da porosidade aparente e de absorção de água. Rio de Janeiro: Associação Brasileira de 
Normas Técnicas. 8p. 2015.

ASTM - AMERICAN SOCIETY FOR TESTING AND MATERIALS. Standard test method for laboratory determination of pulse velocities and ultrasonic elastic constants of rock. D2845. West Conshohocken. 7p. 2008.

ASTM - AMERICAN SOCIETY FOR TESTING AND MATERIALS. Standard practices for preparing rock core as cylindrical test specimens and verifying conformance to dimensional and shape tolerances. D4543. West Conshohocken. 9p. 2008.

ASTM - AMERICAN SOCIETY FOR TESTING AND MATERIALS. Standard test method for compressive strength of dimension stone. C170. West Conshohocken. 2014. 3p.

ASTM - AMERICAN SOCIETY FOR TESTING AND MATERIALS. Standard Test Method for Fundamental Transverse, Longitudinal and Torsional Resonant Frequencies of Concrete Specimens. C215. West Conshohocken. 7p. 2014.

ASTM - AMERICAN SOCIETY FOR TESTING AND MATERIALS. Standard test method for compressive strength and elastic moduli of intact rock core specimens under varying states of stress and temperatures. D7012. West Conshohocken. 9p. 2014.

CPRM - COMPANHIA DE PESQUISA DE RECURSOS MINERAIS - SERVIÇO GEOLÓGICO DO BRASIL. Mapeamento Geológico-geotécnico e delimitação das áreas de risco geológico ao longo do traçado da via do trem de alta velocidade - Relatório da Primeira etapa. São Paulo: Companhia de Pesquisa de Recursos Minerais, 2009.

DOBEREINER, L. Weak Rocks in Brazil. Bulletin of the Int Assoc Eng Geol., v. 42, p. 21-29, 1990.

GALVÁN, V.R. Simulação das propriedades geotécnicas das rochas arenosas brandas por meio de materiais artificiais. São Paulo, 1999, 569p. Tese (Doutorado) - Universidade de São Paulo.

HAACH, V.G.; CARRAZEDO, R.; OLIVEIRA, L.M.F.; CORREAA, M.R.S. Application of acoustic tests to mechanical characterization of masonry mortars. NDT \& E International, v. 59, p. 18-24, 2013.

IPT - INSTITUTO DE PESQUISAS TECNOLÓGICAS DO ESTADO DE SÃO PAULO. Sugestões de Técnicas e Métodos de Investigação Geológico-geotécnica a ser aplicadas ao longo do traçado do TAV entre as cidades do Rio de Janeiro, São Paulo e Campinas. Relatório Técnico 115, p. 372-205, 31p. 2010.

ISRM - INTERNATIONAL SOCIETY FOR ROCK MECHANICS. Commission on testing methods. Part 1: Suggested methods for determining water content, porosity, density, absorption and related properties and swelling and slake-durability index properties. In: International Journal on Rock Mechanics Mining Sciences \& Geomechanics Abstracts. Great Britain, v. 16, n. 2, p. 143-151, 1977.
ISRM - INTERNATIONAL SOCIETY FOR ROCK MECHANICS. Commission on standardization of laboratory and field tests. Suggested methods for the quantitative descriptions of discontinuities in rock masses. In: International Journal on Rock Mechanics Mining Sciences \& Geomechanics Abstracts. Pergamon Press Ltd. Great Britain, v. 15, n. 6, p. 319-368, 1978a.

ISRM - INTERNATIONAL SOCIETY FOR ROCK MECHANICS. Commission on standardization of laboratory and fields tests, Suggested methods for determining sound velocity. In: International Journal on Rock Mechanics Mining Sciences \& Geomechanics Abstracts. Pergamon Press Ltd, Great Britain, v. 15, p. 53-58, 1978b.

ISRM - INTERNATIONAL SOCIETY FOR ROCK MECHANICS ISRM. The ISRM Suggested Methods for Rock Characterization, Testing and Monitoring: 2007-2014. New York: Springer, 292p. 2014.

Kanji, MA .Critical Issues in soft rocks. Journal of Rock Mechanics and Geotechnical Engineering, V.6, N.3, p.186195, 2014

NÓBREGA, C.A. Considerações sobre a caracterização da resistência e deformabilidade em rochas de baixa resistência através de ensaios em laboratório e "in situ". São Carlos, 1985. 106p. Dissertação (Mestrado). Universidade de São Paulo.

PARIZOTTO, J.C.V. Degradação hidromecânica de rochas brandas silto-argilosas. São Carlos, 2015. 231p. Dissertação (Mestrado). Escola de Engenharia de São Carlos da Universidade de São Paulo.

PARIZOTTO, J.C.V., RIBEIRO, R.P., PARAGUASSÚ, A.B. Soft rocks: Relevant Aspects to the Resumption of the studies in Brazilian Geotechnics. In: SIMPÓSIO BRASILEIRO DE MECÂNICA DAS ROCHAS, 2014. Proceedings...Rock Mechanics for Natural Resources and Infrastructure - ISRM Specialized Conference, p. 7

TAYLOR, R.K. Coal measures mudrocks: composition, classification and weathering processes. Quartely Journal of Engineering Geology, v. 21, p. 85-99, 1988.

Submetido em 15 de março de 2017 Aceito em 4 de setembro de 2018 